\title{
Model breaking points conceptualized
}

\section{Citation}

Vig, R., Murray, E., \& Star, J.R. (2014). Model breaking points conceptualized. Educational Psychology Review.

\section{Permanent link}

http://nrs.harvard.edu/urn-3:HUL.InstRepos:11591712

\section{Terms of Use}

This article was downloaded from Harvard University's DASH repository, and is made available under the terms and conditions applicable to Open Access Policy Articles, as set forth at http:// nrs.harvard.edu/urn-3:HUL.InstRepos:dash.current.terms-of-use\#OAP

\section{Share Your Story}

The Harvard community has made this article openly available.

Please share how this access benefits you. Submit a story.

Accessibility 
Running head: MODEL BREAKING POINTS

\section{Model Breaking Points Conceptualized}

Vig, Rozy., Murray, Eileen., \& Star, Jon.R.

2014 


\begin{abstract}
Current curriculum initiatives (e.g. National Governors Association Center for Best Practices \& Council of Chief State School Officers, 2010) advocate that models be used in the mathematics classroom. However, despite their apparent promise, there comes a point when models break, a point in the mathematical problem space where the model cannot, or arguable should not, be used. In this work, we explore the breaking point of the chip model for integer subtraction and the area model for fraction addition. Breaking is inevitable - either because no one model is robust enough to be applicable in a very large problem space and/or because the modifications required to keep the model functioning weaken or even eliminate its benefits. While models are often intended to serve as visual illustrations or embodiments of a concept, adaptions at the model breaking point can turn model use into nothing more than executing the graphical analogue to a not-well-understood procedure. The act of identifying model breaking points illuminates the affordances and constraints of the model. This provides students a unique opportunity to discriminate across mathematical models to develop a meta-level understanding of the relationship between models and the mathematics those models are intended to support.
\end{abstract}

Keywords: Models, Representations, Integer Operations, Fractions 


\section{Model Breaking Points Conceptualized}

The construction and interpretation of models plays a central role in the discipline of mathematics (Bruner, 1966; Cramer \& Wyberg, 2009; Dubinsky, 1991; Hiebert \& Carpenter, 1992; Kaput, 1989; Pape \& Tchoshanov, 2001; Sfard, 1991). In accordance, many educational reform documents advocate that models be used in the mathematics classroom to help students manage, explore, communicate, and interpret mathematical ideas and phenomena (National Council of Teachers of Mathematics, 2000). Implicit in these recommendations is the notion that mathematical models serve to make transparent mathematical concepts that often remain opaque in the conventional mathematical symbol system (Kilpatrick, Swafford, \& Findell, 2001; Panasuk \& Beyranevand, 2010; Vlassis, 2002). Too frequently, students use mathematical symbols in ways that violate the rules of mathematics, such as inappropriately adding a zero when multiplying by 10 (e.g., 2.5 x 10 = 2.50) or incorrectly simplify algebraic expressions (e.g., $\mathrm{a} * \mathrm{a}+3=2 \mathrm{a}+3)$. Over the last $30+$ years, various models have been employed to support student reasoning of mathematics symbols as well as the concepts those symbols are intended to represent (Collins \& Ferguson, 1993; Koedinger, Alibali, \& Nathan, 2008; McNeil \& Jarvin, 2007; Moyer, 2001).

We use the term mathematical model (i.e. model) to refer to "material, visual sketches, paradigmatic situations, schemes, diagrams, and even symbols” that help students manage, document, communicate, or interpret mathematical ideas and phenomena (Van den HeuvelPanhuizen, 2003, p. 13). For the purposes of this work, we make no distinction between models and representations. Furthermore, our use of these terms is not intended to capture mental models or internal representations, which are thought to be abstractions of mathematical concepts that exist in the mind (Battista, 1994; Greeno, 1991; Johnson-Laird, 1983, 1998). Rather, we are 
interested in manifestations of mathematical concepts that exist in the environment and "act as stimuli on the senses” to help one understand those concepts (Janvier, Girardon, \& Morand, 1993, p. 81).

Models can be used in a variety of ways. One common distinction is made between constructed models, where students build models (e.g., drawings and pictures) in order to make sense of mathematical problems, and presented models, the more common practice of presenting students with pre-constructed models in order to highlight for them certain mathematical concepts and procedures (Friel, Curcio, \& Bright, 2001). Our focus here is on the latter. A further complexity concerns the term "modeling," which is typically used to refer to the act of constructing functions to model or represent particular situations, fitting models to data, and using the model to interpret, analyze, and generalize from data (Doerr \& English, 2003; Jonassen \& Strobel, 2006; Mousoulides, Christou, \& Sriraman, 2008; National Governors Association Association \& Council of Chief State School Officers, 2010; Schwarz \& White, 2005; VanLehn, 2013; Zbiek \& Conner, 2006). Although it is an important mathematical practice that can allow students to reason with data in real context, "modeling” falls outside the scope of this paper. Our interest is on the increasingly prevalent use of presented models for illustrating mathematical concepts and procedures; examples of presented models include algebra tiles for exploring the domain of algebra equation solving, geoboards for investigating the geometric relationships between area and perimeter, and tree diagrams for working with probability problems.

Despite their apparent promise, it is clear that models have both affordances and constraints for supporting student reasoning (e.g., Kamii, Lewis, \& Kirkland, 2001). In particular, while a model may be helpful in working with a class of mathematics problems, there comes a point (e.g., as problems become more complex) where the model is no longer applicable 
or useful. We refer to this point as the model breaking point. Consider the common use of circles as a way to illustrate fractions. While it is quite easy to use circles for representing fractions with certain denominators (e.g., powers of 2), it is considerably more difficult to use circles for fractions with denominators such as 7 or 9. Furthermore, circles (and perhaps any other model) are not useful at all for representing fractions with very large denominators such as 19 and 50 . Clearly the utility of circles for illustrating fractions diminishes and even ends at some point; this is the breaking point of the model.

More generally, models are typically developed for a predefined target problem space (see for example Even, 1998; Peled \& Carraher, 2007; Scher \& Goldenberg, 2001; Schnepp \& Nemirovsky, 2001; Schoenfeld, 1986). As we begin to see the value of a model in supporting student reasoning of the mathematics, we attempt to extend the target problem space in natural ways where we might expect the model would still hold. As another example, consider models for positive integer addition (e.g., objects that can be counted), which can support students' thinking as they move from counting to more sophisticated addition strategies. If a model appears effective at helping students see the relationship between quantity and the operation of addition, then it seems natural to extend the use of this model. Can the same model be used to support students' thinking about positive integer subtraction? For (positive and negative) integer addition and subtraction more generally? For non-integral addition and subtraction? For multiplication and division? As with the circle example, it seems straightforward that in the act of applying the model to an extended problem space, it is inevitable that the model breaks. In other words, there comes a point at which the model must either be adapted for the new problem space or it must be abandoned. 
We are aware that one could argue that this point - that all models inevitably break - is obvious: It is clearly inadvisable or even impossible to try to use circles to illustrate fractions with extremely large denominators (e.g., 10,000) or to use counting objects for exploring topics in Calculus. Clearly there comes a point where a model is no longer suitable, reasonable, or the best choice to represent a task. But for a given model, is it possible to identify exactly where this point arises? Our interest here is in exploring where models begin to break - where adaptions to the model may appear necessary to allow the model to continue to be usable with an extended problem space. What types of adaptation to the model preserve the intended illustrative goals of the model and its connection to the mathematics? What types of adaptations move the model (perhaps unintentionally) away from the mathematical ideas that lie at the core of the utility of the model? We show in this paper that models typically break long before the obvious breaking point alluded to above - that models are routinely adapted to extend their usefulness but in ways that lessen or even eliminate their power in illustrating mathematical concepts.

As a way to explore model breaking points, we focus here on two mathematical models the chip model for integer addition and subtraction, and the area model for fraction addition. We focus on the chip and area models due in part on their prevalence in many middle and elementary mathematics curricula in the US (e.g., Everyday Mathematics (Bell, Bell, Bretzlauf, Dillard, \& Hartfield, 2007); Impact Mathematics (Courses 1 \& 2) (Education Development Center, 2009)) as well as because the mathematical content areas of integer and fraction operations are a persistent source of student difficulty, and are key building blocks for later mathematics development (Carpenter, Franke, \& Levi, 2003; Kaput, Carraher, \& Blanton, 2008; Knuth, Alibali, Hattikudur, McNeil, \& Stephens, 2008). 
In the two sections to follow, we explore the chip model and the area model, with special consideration of the breaking point, including potentially productive and counter-productive adaptations, of these models. We then discuss model breaking points more generally, with particular interest in how to leverage the construct of model breaking points in the mathematics classroom.

\section{Chip Model for Integer Operations}

Many models have been used to try to help students better conceptualize negative numbers and operations with integers (Kilpatrick et al., 2001). Some models are situational, where discrete objects are not integral to the use of the model, including positive and negative thinking (Petrella, 2001; Whitacre et al., 2012); balloons and sandbags (Reeves \& Webb, 2004); debts and assets (Ball, 1993; Gregg \& Gregg, 2007); net worth (Stephan \& Akyuz, 2012; Stephan, 2009); rewards and punishments (Shore, 2005); elevators (Ball, 1993) and temperature (Altiparmak \& Özdoğan, 2010). Other models for working with integers rely upon discrete objects such as counters (Liebeck, 1990) or colored chips (Flores, 2008; Lappan, Fey, Fitzgerald, Friel, \& Phillips, 2006).

We focus here on the colored chips, better known as the chip model. As it is typically used, the chip model uses two distinct objects, such as black chips and red chips, to represent positive and negative numbers, respectively. When using the chips to model integer operations, addition is conceived as combining objects while subtraction is most often interpreted as taking away objects. To consider how the chip model can be used to model integer subtraction, it is useful to specify the full range of problem types that fall within the domain of integer addition and subtraction (see Table 1). For both addition and subtraction problems, there are six types of problems, depending on the signs (positive or negative) of the two quantities in the problem and 
the relative magnitude of each. Note that in addition problems, both quantities are referred to as addends, while in subtraction problems, the quantity from which another is subtracted is called the minuend while the quantity being subtracted is called the subtrahend. In the following paragraphs, we consider how the chip model can be used for exploring each of these six problem types, in service of our larger goal of considering when and why this model might break for integer subtraction.

\section{INSERT TABLE 1 HERE}

First, consider the first four types of addition problems, A-1, A-2, A-3, and A-4. In order to accurately and faithfully depict the mathematics of integer operations for these problem types, it is necessary to stipulate only one rule that maps the mathematics to the chips - namely, that each black and red chip represents the same absolute quantity - typically one black chip is the quantity 1 and one red chip is the quantity ${ }^{-} 1$. With this rule, addition problems of both types are relatively straightforward with the chips. To add $5+3$ (A-1), which is modeled with 5 black chips added to 3 black chips, one merely combines the chips to result in a collection of 8 black chips, which represents the quantity 8 . Similarly, to add ${ }^{-} 5+{ }^{-} 3$ (A-2), one merely combines 5 red chips with 3 red chips to yield 8 red chips, which represents the quantity of ${ }^{-} 8$. (The reasoning for the use of the model in types A-3 and A-4 is identical.) Note that in these types of addition problems, the use of the model is quite consistent with how students typically think about addition with whole numbers and also how addition is modeled with other types of concrete objects, where the quantity that a collection of concrete objects represents is merely the number of objects in the collection.

Using the chip model for subtraction problem types S-1 and S-2 is identical to what was described for the first four types of addition problems, in that only the rule described above - that 
each black and red chip represents the same absolute quantity - is needed. To subtract 5 - 3 , one merely takes away 3 black chips from the collection of 5 black chips, leaving 2 black chips, which represents the quantity of 2 . Similarly, to subtract ${ }^{-5}-{ }^{-} 3$, one takes away 3 red chips from the collection of 5 red chips, leaving 2 red chips, which represents the quantity of ${ }^{-} 2$. Again, it is important to note that for these two subtraction problem types, the relationship between the chips in a collection and the quantity that the chips represents is straightforward - the quantity is merely the number of chips in the collection.

However, it quickly becomes clear that this mapping between the model and the mathematics - the quantity that a collection represents is the number of chips in the collection is not always true. Consider problem type $\mathrm{A}-5,5+{ }^{-}$. . To add $5+{ }^{-} 3$, one begins with 5 black chips and 3 red chips and then combines these chips into a collection. But what quantity does a collection of 5 black chips and 3 red chips represent? As above, students' prior experience might suggest that a collection of 5 black chips and 3 red chips represents the quantity 8 (as there are 8 objects in the collection). Thus, in order to correctly interpret this collection of chips as a quantity, it is necessary to identify a relationship between black and red chips - e.g., how black and red chips can be combined. Thus a second rule that maps the mathematics to the chips is required - namely, that when a black chip is paired with a red chip, the two chips 'cancel', in the same way that when the quantities $1^{\text {and }}{ }^{-} 1$ are combined, the result is zero. Thus, in the collection of 5 black chips and 3 red chips, we can now pair the 3 red chips with 3 black chips. These three 'zero pairs' are then removed from the collection, leaving only 2 black chips, representing a quantity of 2 . Similarly, to add ${ }^{-5}+3$ (A-6), one begins with 5 red chips and 3 black chips. Then each of the 3 black chips is paired with 3 red chips. These three zero pairs are removed from the collection, leaving 2 red chips, representing the quantity of ${ }^{-} 2$. 
Note that for this second rule, there is nothing inherent in the use of chips that suggests its need. If one considers how chips are used in the game of checkers, for example, different colored chips represent two teams playing against each other. In checkers, the chips have no value and different colored chips do not combine to cancel each other out. (A similar point could be made using games other than checkers, including Reversi and the Chinese game of Go - both of which use similar looking chips in ways that are different than checkers.) Inevitably there is a duality in the use of chips (McNeil \& Jarvin, 2007; McNeil, Uttal, Jarvin, \& Sternberg, 2009; Uttal, O’Doherty, Newland, Hand, \& DeLoache, 2009), in that the same model is used in different ways, depending on whether one is playing a game or doing mathematics. This duality makes the second rule discussed above necessary in order to make the chip model align with the mathematics that the model is supposed to represent and illuminate; “... a given manipulative needs to be represented not only as an object in its own right, but also as a symbol of a mathematical concept or procedure” (McNeil \& Jarvin, 2007, p. 313). Students may face initial confusion in learning to use the chips in (for them, new) ways that model mathematics. Yet, the affordances of using the model in allowing students to employ their previous experiences with discrete objects and whole numbers, along with the straight-forward application of two basic rules described above, has been shown to foster students' mathematical understanding of particular integer operations (Bolyard \& Moyer-Packenham, 2012; Flores, 2008). The inclusion of the second rule - that one black and one red chip 'cancel' - is an adaption of the chip model in order to allow the model to be used with an expanded problem space.

However, using the chips to model the remaining subtraction problem types requires further adaptation of the chip model, to the point where one might wonder whether a breaking point has been reached. Consider problem type S-3, $3-5$. We begin with a collection of 3 black 
chips, and the problem indicates that we should take away 5 black chips from the collection. Yet there are not enough black chips in the collection - only 3 are present. How can the model be applied to this situation? What adaption of the model is required?

Guidance can be found if we look to other kinds of mathematical problems outside of the chip model. When learning how to perform subtraction problems such as $14-9$, students are introduced to a strategy commonly called regrouping that is tightly linked to the important mathematical concept of place value. Within the base-10 system, the number 14 is composed of one 'ten' and 4 'units,' while the number 9 is 9 units. When we try to subtract $14-9$, we appear to be faced with an impasse: since 14 seems to have only 4 units, how can we subtract 9 units? But instead of thinking of 14 as one ten and 4 units, we can rename it as 14 units (where 1 ten is renamed or regrouped as 10 ones), and this allows us to subtract 9 units from 14 units to obtain an answer of 5 units. (This strategy is called 'borrowing' by some, yet regrouping is the more standard term at present, as a way to emphasize the conceptual nature of the number renaming.) Counting strategies that students have previously used for problems such as $14-3$ may not work when applied to problems such as 14 - 9; regrouping allows for consideration of these new problem types.

A similar situation can be observed within the chip model. As noted above, the chip model appears to break when used in problems such as $3-5$, because the collection (of 3 black chips) does not include 5 black chips to take away. However, if a regrouping strategy is applied, 3 can be renamed so as to introduce the necessary chips to then perform the subtraction. Note that 3 can be renamed in many ways, including $\left(4+{ }^{-} 1\right),\left(5+{ }^{-} 2\right),\left(6+{ }^{-} 3\right)$, etc. If 3 is renamed in a way that insures that at least 5 black chips are available to be subtracted, then the renaming will allow the model to be used for this problem. Rewriting 3 as $\left(4+{ }^{-} 1\right)$, which changes the problem 
from $3-5$ to $\left(4+{ }^{-} 1\right)-5$ does not accomplish this goal, as only 4 black chips (and 1 red chip) are in the collection - it is still not possible to subtract 5 black chips. But if 3 is renamed as (5+ ${ }^{-}$ 2 ), changing the problem to $\left(5+{ }^{-} 2\right)-5$, the model holds, as illustrated in Figure 1 , with a solution of ${ }^{-} 2$.

\section{INSERT FIGURE 1 HERE}

This strategy of renaming is the key that enables the chip model to be applicable on all of the remaining types of subtraction problems. For ${ }^{-} 3-{ }^{-5}$ (S-4), we cannot take away 5 red chips, since the collection only contains 3 red chips. However, if we rename ${ }^{-} 3$ as $\left({ }^{-} 5+2\right)$, the problem becomes $\left({ }^{-} 5+2\right)-{ }^{-} 5$ and it is possible to take away 5 red chips. Similarly, for $5-{ }^{-} 3(\mathrm{~S}-5)$, it is not possible to take away 3 red chips from a collection that only includes 5 black chips. But if 5 is renamed as $\left(8+{ }^{-} 3\right)$, transforming the problem to $\left(8+{ }^{-} 3\right)-{ }^{-} 3$, we can take away 3 red chips, leaving 8 black chips. Finally, for ${ }^{-} 5$ - 3 (S-6), although we cannot take away 3 black chips from a collection that only includes 5 red chips, we can rename ${ }^{-5}$ as $\left({ }^{-} 8+3\right)$. The resulting problem, $(-8+3)-3$ allows us to use the model to obtain a solution of ${ }^{-} 8$.

Although the preceding discussion illustrates how the chip model can be used to model all types of integer addition and subtraction problems, doing so required two adaptations of the model. Recall that in its most basic form, the chip model only needed to share features with models using other discrete objects that could be counted; this basic chip model allowed for the representation of problems such as $5+3$ or ${ }^{-5}+{ }^{-} 3$. But two new model rules were subsequently required for more complicated problems. The first dealt with the situation where a collection contained both red and black chips (e.g., in the problem $5+{ }^{-} 3$ ); mapping such a mixed collection to a quantity required the invention of zero pairs, where an equal number of red and black chips cancel each other out. The second dealt with the situation where there were insufficient chips to 
perform a given subtraction, such as in the problem $3-5$. Using chips to model this kind of problem required a regrouping or renaming of the minuend in a way such that there were enough chips in the collection to subtract.

We propose that the first modification can be construed as an attempt to adapt the model to better align with the mathematics, thus preserving the relationship between the model and the mathematics, and not representing a breaking point of the model. However, the second modification is an attempt to rescue the model - to adapt it in a way that reaches beyond the natural relationship with the mathematics - thus representing a breaking point. In other words, the chip model breaks when used with subtraction problems of types S-3, S-4, S-5, and S-6.

To understand this breaking point more clearly, we discuss two ways the chip model breaks for these problems. First, the renaming that is necessary to make the model work is not linked to important mathematical concepts. The renaming is rather a trick that enables students to complete the problem. This represents the short-term goal of using the chips with the problem rather than the larger goal of illuminating important mathematics. For instance, in the $14-9$ example used above, we talked about renaming as changing 1 ten and 4 ones as 14 ones. This type of renaming or regrouping enables us to do the problem but also reinforces key mathematical ideas around place value and our base-ten number system. On the other hand, the renaming that is necessary for using the chip model for the problem $14-9$ would involve renaming 14 as $5+9$, thus changing the problem to $(5+9)-9$. Although this latter renaming is mathematically valid, it has no conceptual purpose and is solely concerned with restructuring a specific problem in order for the model to be applicable.

The second way the model breaks is that the renaming necessary draws upon exactly the same knowledge that the model is supposed to illustrate - if a student can regroup in the way 
necessary to employ the chips, then we argue the student no longer needs the model. For example, students need to know that 3 can be renamed as $5+{ }^{-} 2$ in order to model the problem 3 - 5. If a student knows that $5+{ }^{-} 2$ is 3 without using the model, then is the model necessary for the student to determine $3-5$ ?

Our analysis suggests that the chip model breaks for subtraction problem types S-3, S-4, S-5, and S-6; we believe that the identification of when (in the problem space) and why this model breaks is significant. These problems in which the chip model breaks leads us to very important features of the learning landscape for integer subtraction. Students' conception of subtraction as taking away is challenged by the fact that there is not enough to take away, which is exactly the place where students are likely to struggle with integer subtraction. This conceptual hurdle is thus the precise location where a good model is needed to facilitate student understanding. Further, these types of subtraction problems are arguably the exact problems that this model was designed to illuminate. Unfortunately, the adaptations necessary to enable the model to function with these problems signals the model's inadequacies. The model breaks when we attempt to apply it to particular subtraction problems, and adaptations only serve to extend the applicability of the model but fail to provide conceptual support for students, which is perhaps the chief aim of the model in the first place.

We now move to area models for fraction addition, with the goal of a similar analysis about when and why this model breaks.

\section{Area Model for Fraction Addition}

Area models are often used to support student understand of fractions (Corwin, Russell, \& Tierney, 1991; Empson, 1999; Hecht \& Vagi, 2012; Hunting, Davis, \& Pearn, 1996; Kong, 2005; Saenz-Ludlow, 1994; Streefland, 1993; Tzur, 1999). An area model is a visual depiction of 
area (generally in the shape of a rectangle) that highlights the part-whole relationship of a fraction. For example, an area model that depicts the fraction $\frac{1}{4}$ would show a rectangle (the 'whole'), divided into four equal parts, with one of the parts shaded. In order for students to accurately construct and/or interpret an area model, they must know that the denominator of the depicted fraction represents the total number of equal size parts that make up the whole, while the numerator represents the number of shaded parts within that whole. Research shows that students are quite adept at correctly constructing area models of a given proper fraction and correctly interpreting a canonical area models to arrive a fraction (NAEP, 2009; Saxe, Taylor, McIntosh, \& Gearhart, 2005).

Here we explore the use of area models for fraction addition. Although area models were introduced initially to support students' meaning about fractions (especially to illuminate the part-whole nature of fractions), this model is also increasingly used with fraction operations (Mix, Levine, \& Huttenlocher, 1999; Olive, 1999). What are the conditions or rules under which this model is effective at supporting student understanding of fraction addition? At what point does the model begin to lose its effectiveness in illuminating key concepts related to fraction addition? In other words, at what point does the model break, and why?

As above, we begin our examination of area models for fraction addition by identifying salient aspects of the problem space. Although there are many ways that the landscape of fraction addition problems could be parsed, of interest here is the distinction between fraction addition problems where (a) both addends are between 0 and 1 , such as $\frac{1}{6}+\frac{1}{4}$, and (b) one or both addends are larger than 1 , such as $\frac{1}{3}+\frac{3}{2}$ or $\frac{7}{4}+\frac{5}{3}$. 
First, consider how one might represent fractions where both addends are between 0 and 1 using an area model. We can assume that representing $\frac{1}{4}$ and $\frac{1}{6}$ as individual fractions using an area model would be straightforward to a student who has some familiarity with area models. But how can the model be used to support understanding of the process of adding two fractions? Nothing in students' prior experience depicting individual fractions as area models provides guidance about acceptable and unacceptable ways of using area models for fraction addition. It is, therefore, conceivable that students might combine the two individual models for $\frac{1}{4}$ and $\frac{1}{6}$ as shown in Figure 2, as this is how discrete objects (including the chips described above) are typically combined. Furthermore, there is nothing inherent to the area model that would suggest to students that the size of the area model whole must be equal for the two given fractions; as a result, a student might depict $\frac{1}{\mathbf{4}}$ and $\frac{1}{6}$ with different size wholes and then combine them, as shown in the bottom panel of Figure 2.

\section{INSERT FIGURE 2 HERE}

Although perhaps intuitive, neither of these ways of using area models for fraction addition is correct. Why? When symbolically adding fractions, two important conceptual considerations are required. First, a key concept that is integral to fraction addition and depicted in the model is the preservation of the unit whole. When performing fraction addition symbolically, the unit whole is implicit; we do not write, $\frac{1}{4}$ (of one) $+\frac{1}{6}$ (of one) $=\frac{5}{12}$ (of one). Yet within the model and graphically, the unit whole is visually apparent. Therefore, when using area models for fraction addition, care must be taken to insure that both wholes are the same size. Second, in order to add two fractions together, the parts of each of the fractions should 
be the same size. Having equal size parts across the two area modes ensures correct construction and interpretation of the final area model. That is not to say that one cannot arrive at correct solution to using different size parts, but the task becomes significantly more difficult, particularly as the relative size of the parts becomes smaller and the parts do not share a multiplicative relationship with one another (e.g., $\frac{1}{2}+\frac{1}{4}$ versus $\frac{1}{8}+\frac{1}{9}$ ). Thus, in order for the area model to provide a mathematically accurate depiction of fraction addition, both of these requirements must be met visually: $\frac{1}{4}$ and $\frac{1}{6}$ should be depicted with rectangles that are the same size, and before adding, the parts of each of the wholes should be the same size.

In terms of the use of the model, constructing fractions with wholes that are the same size is straightforward. But it is this second consideration that provides the greatest challenge to the model. What does it mean for the parts to be the same size, given that $\frac{\mathbf{1}}{\mathbf{4}}$ of a whole is bigger than $\frac{1}{6}$ of the same whole? Using the model, how can two fractions with different sized parts be changed so that they have the same sized parts?

Consideration of a simpler case of fraction addition helps make this more apparent. In Figure 3, below, a model for adding $\frac{1}{4}+\frac{1}{2}$ is shown. By splitting the one shaded and one unshaded parts of $\frac{1}{2}$ into two equal pieces, we then create models for $\frac{1}{4}$ and $\frac{1}{2}$ with the same size parts, which can then be added to yield $\frac{3}{4}$. 
Thus, to successfully model fraction addition using this model, one must (1) first create wholes that are the same size, then (2) each fraction must be transformed such that both fractions have pieces that are the same size, and then finally (3) fractions can be added by moving the shaded parts of one area model into the non-shaded parts in the other area model. It is important to note that there is nothing inherent to the area model itself that identifies this procedure for how to use the model to depict fraction addition - the procedure has been invented so that area models behave (and yield the same answer) as symbolic computation of fractions.

Returning to the case of $\frac{1}{4}+\frac{1}{6}$, consider how one might use the model to address the challenge of constructing equal size parts across the area model depicting $\frac{1}{\mathbf{4}}$ and the area model depicting $\frac{1}{6}$. The model does not provide guidance on how to create equal size pieces from fourths and sixths. Techniques that might be intuitive or visually executable within the model, such as repeatedly partitioning parts into halves (e.g., 4ths into 8ths into 16ths; 6ths into 12ths into 24ths) would, for this problem, only work for very tiny parts (48ths), and more generally would often not be fruitful at all. But perhaps through trial and error outside of the model (e.g., not using the model at all but thinking symbolically about the least common multiple of 4 and 6), one might arrive at the construction given in Figure 4 . Here the fourths in the $\frac{\mathbf{1}}{\mathbf{4}}$ area model are each equally partitioned into thirds and the sixths in the $\frac{1}{6}$ area model are each equally partitioned into halves resulting in two area models with 12 equal size parts. At this point the shaded parts from one area model can be moved into the non-shaded parts of the other to arrive at the correct sum of $\frac{5}{12}$. 


\section{INSERT FIGURE 4 HERE}

As we expand the problem space to include fractions greater than one, it becomes clear that the procedures for performing fraction addition in the model become considerably more complex, and the task of using area models for fraction addition increasingly tedious. Consider the problem $\frac{1}{4}+\frac{3}{2}$, given in Figure 5. First, the requirement about preserving the whole must be accomplished with three area models instead of two, as three rectangles are needed to represent the two given fractions (since $\frac{3}{2}$ is greater than one whole). And again, the size of the area model whole for each must be the same (see Figure 5, top panel). Second, the requirement of equal sized parts must also be accomplished with three area models instead of two. This could be done by partitioning each of the halves in the two area models depicting $\frac{3}{2}$ into 2 equal size parts to arrive at 4 equal size parts across all three area models (see Figure 5, middle panel). Alternatively, the student could partition each of the fourths into 2 equal parts and each of the halves into 4 equal parts result in a total of 8 equal size parts across the three area models. Both techniques lead to a correct sum. Third, once there are three equal size area models with equal number of equal size parts, the shading must be moved between the two area models depicting fractions less than one, leaving the completely filled area model intact (see Figure 5, bottom panel). As a final step, student must interpret the two shaded area model to arrive at $1 \frac{3}{4}$ or $\frac{7}{4}$.

\section{INSERT FIGURE 5 HERE}

As we move from the problem space involving fractions less than one to the problem space involving fractions greater than one, it is clear that the procedure for using area models for fraction addition are made more complex. The increase in complexity is tied explicitly to the 
condition that the unit whole must be preserved when using area model for fraction addition. As noted above, this condition plays a central role in the perceived benefits of the area model, in that preserving the unit whole is both a core concept related to fraction addition and also visually integral to the use of the model. Yet as the problem space for fraction addition expands, this requirement becomes less a reminder about the conceptual basis for fraction addition and more of a procedural hurdle to successful computation. As shown in the above example, when dealing with fractions greater than one, an additional area model is needed. (When both fractions are greater than one, or even when one or more of the fractions is much greater than one (e.g., $\frac{\mathbf{9}}{4}$ ), even more rectangles are needed, making the task even more complex or tedious.) Executing the procedure for working within the model becomes more and more tedious, which also increases the likelihood of error. The model loses its value in illuminating important conceptual ideas related to fraction addition and instead is a computational device, where one can arrive at the sum of two fractions by carefully following the steps of an intricate procedure.

Our contention is that, as the problem space expands, the area model for fraction addition breaks. The model no longer becomes useful, especially for fraction addends greater than one, for two reasons. First, as fraction addition problems become more complex, it is necessary to do more and more computational work outside of the model to enable one to use the model. For example, determining the least common multiple of two denominators is a task that would need to be done symbolically without the model, so that the correct drawing within the model could be completed. The model provides no support for this computation, except in some special circumstances such as addition of fractions with denominators that are multiples of each other.

Second, and especially when working with fractions greater than one, the procedural steps required to model fraction addition are sufficiently complex and tedious that likely little 
attention is paid to the visually depiction of important concepts in the model such as equal size whole and pieces. A central benefit of the model is that it visually depicts key concepts, in essence keeping these important mathematical ideas present and active during the fraction addition process. Preserving the whole, and obtaining equal sized parts prior to adding, are two important principles underlying fraction addition; the area model formalizes these principles into its procedure for fraction addition. Yet as using the model because increasing tedious and complex, it seems unlikely that students attend to these conceptual principles - their full attention is required for merely completing the computation. In fact, as the problem space expands, it is arguably easier to do the computation without the model, using only symbols. If computation with an area model involves execution of the steps of a procedure, and if (for certain problems) these procedural steps are comparable in terms of complexity to the procedural steps of the symbolic calculation, then why would using the model procedure for fraction addition be preferable to using the symbolic computation procedure? When the complexity of the model procedure approaches and exceeds the complexity of the symbolic procedure, this seems to be an indicator that the model has broken.

\section{Discussion}

In our analysis of the chip model for integer operations and the area model for fraction addition, we sought to understand when and why the models break. With the chip model, we identified a range of problem types involving subtraction of integers where we argued that the model breaks. This breaking point is evident when significant adaptations were required to keep the model functional - adaptations that did not reinforce the key concepts that the model sought to illuminate. Similarly, with the model for fraction addition, we also identified a range of problem types where the model breaks. At this breaking point, we found that the procedures 
required to use the model became overly complex, lost focus on conceptual underpinnings, and were tedious. In both of these models, our identification of the breaking point helped us learn about the affordances and constraints of these models for supporting students' reasoning about fraction addition and integer operations.

In addition, our analysis also raised broad questions about the value of models in general. In particular, precisely what is the added value of a model, and how do adaptations of the model improve or impede its added value for student learning? Is the value of a model in its ability to help students understand key mathematical concepts that conventional math notation fails to make salient (Kilpatrick et al., 2001; Panasuk \& Beyranevand, 2010; Vlassis, 2002)? With fraction addition, perhaps the area model highlights the importance of preserving the unit whole and adding only same-size pieces - both of which are not especially evident in the symbolic procedure. Alternatively (or in addition), perhaps the value of a model is to enable students to discover procedures for working with the conventional mathematical notation. With integer operations, perhaps because the chip model requires students to rename integers in several ways, this helps prepare students to work more accurately and efficiently with symbolic operations on integers. Our reading of the literature indicates insufficient attention to a careful articulation of the goals for particular models, and our examination of model breaking points provided an opportunity for us to engage with this issue.

There appears to be a general and often unstated assumption that models are a useful and important means for supporting student understanding of mathematical concepts (McNeil \& Jarvin, 2007; Moyer, 2001). However, our analysis demonstrates a considerably more complex picture of how and when models can support conceptual knowledge growth in students. It appears that the mathematical concepts supported by a model can be obscured or even lost 
entirely in the act of using the model to arrive at an answer to computational mathematics problem. Furthermore, as the problem space is made more complex, the rules that guide the use of the model can become disconnected from the underlying mathematics and the procedures for making the model fit the mathematics can at times become more cumbersome than the procedures of the symbolic algorithm. These are all instances in which we believe a model breaks. If models are intended to serve as visual illustrations or embodiments of a concept, adaptions at the model breaking point can turn model use into nothing more than executing the graphical analogue to a not-well-understood procedure. Before they break, models can be illustrative of important ideas; after they break, models merely become a (non-symbolic) computational device.

One reaction to our analyses, particularly our claims that the chip model for integer operations and the area model for fraction addition break, might be to suggest that other, alternative models for these content areas be used (Altiparmak \& Özdoğan, 2010; Ball, 1993; Gregg \& Gregg, 2007; Ni, 2000; Reeves \& Webb, 2004; Saxe et al., 2005; Stephan \& Akyuz, 2012). If these models are inadequate, perhaps others can be chosen or developed that work better. While it may be true that other models can be used for these content areas, selection of alternative models does not offer an escape from the reality that all models require adaptations that may lead them to eventually break. For example, even in the real life context of debt and credit, which has been shown to help improve students' understanding of integers and integer operations (Stephan \& Akyuz, 2012) the idea of removing more debt than one has (e.g., ${ }^{-3}-{ }^{-5}$ ) does not make sense in terms of the model and thus the real life context must be suspended in order to perform the operation. Breaking is inevitable - either because no one model is robust enough to be applicable in a very large problem space and/or because the adaptations required to 
keep the model functioning weaken or even eliminate its benefits. Therefore, even if another, alternative model is applicable for a wider variety of problem types in a given content area, students will still eventually need to grapple with the alternative model's breaking point. Thus, with respect to the larger issue of model breaking points, we believe that it is not a question of if they break, but when.

But if all models eventually break and students need to pay attention to when and why this happens, one might reasonably ask whether models should be used for mathematics instruction at all. Does the benefit of using a model up to the point that it breaks outweigh the potential difficulty and/or confusion caused by abandoning the model or taking up a new model? We would speculate that models still serve a conceptually illuminating function for many mathematical concepts, including integer operations and fraction addition, and are therefore still useful for certain types of problems. For example, with respect to integer addition, the chip model is helpful in illustrating the commonalities and differences between integer and whole number addition (Liebeck, 1990). Furthermore, attention to the breaking point (when and why) offers an opportunity to engage with concepts that might otherwise be masked by simply working with the mathematical symbols (e.g., understanding why $5-{ }^{-3}=5+3$ ). In the case of fraction addition, area models make salient the unit whole concept of fractions; a concept which then limits how students can or cannot operate with area models. A similar constraint does not exist in the case of fraction notation, leading to common misconceptions about fraction addition such as the common error of adding both numerators and denominators (e.g., $\frac{1}{4}+\frac{1}{6}=\frac{2}{8}$ ) (Bottge, Ma, Gassaway, Butler, \& Toland, 2013). Certainly a key benefit of models is their use in clarifying mathematical concepts. Our contention here is that when and how models break also can serve a conceptually illuminating function. Models should not be abandoned merely 
because they break, but rather we advocate taking advantage of models' breaking points in the further service of exploring key concepts.

Note as well that students could still use a model beyond its breaking point, as long as the model does not become simply a computational device disconnected from underlying concepts. We believe that if students are engaged in unpacking the affordances and constraints of whichever model has been presented, this activity could be used to support conceptual understanding of the underlying mathematics. Considering the area model with fraction addition, we illustrate above how the procedural steps required to model particular types of problems are sufficiently complex and tedious. This diverts attention from the visual depiction of important concepts in the model (e.g., unit whole and equal size pieces). However, if students are able to discuss the importance of unit whole and equal size pieces and understand how and why the area model could be used to illustrate fraction addition in a different notation system, they can engage in mathematical activity that involves the coordinating of and transitions between different notation systems (Lesh, Post, \& Behr, 1987; Panasuk \& Beyranevand, 2010; White \& Pea, 2011).

With respect to integer subtraction, there is a class of problems for which the adaptations needed to use the chip model fail to connect to key mathematical ideas (e.g., place value and base-ten). These examples are indications that the models have broken - that is, computation within the model requires an increasing amount of work that is done outside of the model. And it is at this point in the model use that students can take a step back to reevaluate the use of the model, its purpose, and future work within a specific mathematical domain. If it is inevitable that students will eventually need to desert the model, the ability to see and understand the point at which the model breaks and why can facilitate this abandonment. As the model begins to break, 
there comes a point when using the model becomes cumbersome, requiring students to employ extra rules. If a student understands the nature and purpose of these rules, we argue that this may in fact help students better understand the problem space, including the characteristics of number and relationships among quantities.

\section{Conclusion}

Models play an increasingly prominent and important role in mathematics teaching and learning throughout the elementary and secondary grades (Gürbüz, 2010; Schnepp \& Nemirovsky, 2001; Sherman \& Bisanz, 2009). The present work contributes to research that seeks to understand how models can be used productively to support student learning. Despite their prevalence and popularity, it is clear that sometimes models do not fulfill their promise: students become dependent on models for performing computations such that they are unable or unwilling to engage without the model, and/or a model no longer serves to highlight the important concepts that it was designed to showcase. We claim here that models break - there comes a point where models no longer work as desired. This breaking point, including how, when, and why models break, is important for researchers, teachers, and even students to understand.

In terms of classroom practice, our argument is not to do away with models nor is it to restrict models to a narrowly defined space. Rather, we contend that models should be extended for the very purpose of finding the model breaking point; that the true value in using presented model can be drawn by having students reason through the problem space in which a model works and the point at which the model fails to work. Consider an alternative purpose of using a presented model, one in which the goals is not simply to visually highlight a mathematical concept or to map to a mathematical procedure, but one in which the teacher helps students find 
the point at which a concept cannot be highlighted without adapting the model or the point at which the procedure cannot be mapped without adapting the model. To arrive at this model breaking point, the teacher supports students in keeping the model fixed, expanding the problem types, and asking, “Does it [the model] still work?” If it does, then the students continue in the extension process. If the model fails to work, then the teacher might ask students questions that prompt them to identify the breaking point, such as, "What changes are necessary to make the model work in this expanded problem space?” In this way the model becomes a powerful tool for supporting mathematical reasoning. Such an activity is not intended to be a check on the algorithm nor is it about getting to an answer. Rather, the active pursuit of discovering model breaking points offers students a unique opportunity to grapple with the underlying mathematics while also learning the affordances and constraints of using models as tools for and tools of mathematical reasoning.

How can teachers identify when a model is ultimately not helping students? First, teachers might notice that continued use of the model (by both students and the teacher) requires significant adaptations. As noted above, the need for adaptations might signal the need to transition from using the model to conversations about when and why the model breaks. And second, teachers can look for signs that the primary use of the model has transitioned away from illustrating concepts to instead serving as a computation device. If students appear dependent on the model for calculations and/or the computation involved in the use of the model seems more complex than symbolic computations without the model, this may be an indication that the model is no longer useful for supporting students’ learning. 
Although our analysis is limited in that we have explored only two models, focusing on only two modest mathematical content domains, we nevertheless hope that our interest in the breaking point of models can lead to continued investigations of these and other models. 


\section{References}

Altiparmak, K., \& Özdoğan, E. (2010). A study on the teaching of the concept of negative numbers. International Journal of Mathematical Education in Science and Technology, 41(1), 31-47.

Ball, D. L. (1993). With an eye on the mathematical horizon: Dilemmas of teaching elementary school mathematics. The Elementary School Journal, 93(4), 373-397.

Battista, M. T. (1994). On Greeno’s environmental/model view of conceptual domains: A spatial/geometric perspective. Journal for Research in Mathematics Education, 25(1), 86-94.

Bell, M., Bell, J., Bretzlauf, J., Dillard, A., \& Hartfield, R. (2007). Everyday Mathematics, Grade 3. Chicago, IL: McGraw-Hill.

Bolyard, J., \& Moyer-Packenham, P. (2012). Making sense of integer arithmetic: The effect of using virtual manipulatives on students’ representational fluency. Journal of Computers in Mathematics and Science Teaching, 31(2), 93-113.

Bottge, B. A., Ma, X., Gassaway, L., Butler, M., \& Toland, M. D. (2013). Detecting and correcting fractions computation error patterns. Exceptional Children, 80(2), 237-255.

Bruner, J. S. (1966). Towards a Theory of Instruction. Cambridge, MA: Harvard University Press.

Carpenter, T. P., Franke, M. L., \& Levi, L. (2003). Thinking Mathematically: Integrating Arithmetic and Algebra in Elementary School. Portsmouth, NH: Heinemann.

Collins, A., \& Ferguson, W. (1993). Epistemic forms and epistemic games: Structures and strategies to guide inquiry. Educational Psychologist, 28(1), 25-42. 
Corwin, R. B., Russell, S. J., \& Tierney, C. (1991). Seeing Fractions: A Unit for the Upper Elementary Grades. Sacramento, CA: California Department of Education.

Cramer, K., \& Wyberg, T. (2009). Efficacy of different concrete models for teaching the partwhole construct for fractions. Mathematical Thinking and Learning, 11(4), 226-257.

Doerr, H. M., \& English, L. D. (2003). A modeling perspective on students’ mathematical reasoning about data. Journal for Research in Mathematics Education, 34(2), 110-136.

Dubinsky, E. (1991). Reflective abstraction in advanced mathematical thinking. In D. Tall (Ed.), Advanced Mathematical Thinking (pp. 95-126). Dordrecht, The Netherlands: Kluwer Academic Publishers.

Education Development Center. (2009). Impact Mathematics. New York, NY: Glencoe/McGraw-Hill.

Empson, S. B. (1999). Equal sharing and shared meaning: The development of fraction concepts in a first-grade classroom. Cognition and Instruction, 17(3), 283-342.

Even, R. (1998). Factors involved in linking representations of functions. The Journal of Mathematical Behavior, 17(1), 105-121.

Flores, A. (2008). Subtraction of positive and negative numbers: The difference and completion approaches with chips. Mathematics Teaching in the Middle School, 14(1), 21-23.

Friel, S. N., Curcio, F. R., \& Bright, G. W. (2001). Making sense of graphs: Critical factors influencing comprehension and instructional implications. Journal for Research in Mathematics Education, 124-158.

Greeno, J. G. (1991). Number sense as situated knowing in a conceptual domain. Journal for Research in Mathematics Education, 170-218. 
Gregg, J., \& Gregg, D. U. (2007). A context for integer computation. Mathematics Teaching in the Middle School, 13(1), 46-50.

Gürbüz, R. (2010). The effect of activity-based instruction on conceptual development of seventh grade students in probability. International Journal of Mathematical Education in Science \& Technology, 41(6), 743-767.

Hecht, S. A., \& Vagi, K. J. (2012). Patterns of strengths and weaknesses in children's knowledge about fractions. Journal of Experimental Child Psychology, 111(2), 212-229.

Hiebert, J. \& Carpenter, T. P. (1992). Learning and teaching with understanding. In D. Grouws (Ed.), Handbook of Research on Mathematics Learning and Teaching, (pp. 65-97). New York, NY: Macmillan Publishing Company.

Hunting, R. P., Davis, G., \& Pearn, C. A. (1996). Engaging whole-number knowledge for rational-number learning using a computer-based tool. Journal for Research in Mathematics Education, 27(3), 354-379.

Janvier, C., Girardon, C., \& Morand, J. C. (1993). Mathematical symbols and representations. In P. S. Wilson (Ed.), Research Ideas for the Classroom: High School Mathematics, (pp. 79-102). Reston, VA: National Council of Teachers of Mathematics.

Johnson-Laird, P. N. (1983). Mental Models: Towards a Cognitive Science of Language, Inference, and Consciousness. Cambridge: MA: Harvard University Press.

Johnson-Laird, P. N. (1998). Imagery, visualization, and thinking. In J. Hochber (Ed.), Perception and Cognition at the Century’s End, (pp. 441-467). San Diego, CA: Academic Press. 
Jonassen, D. H., \& Strobel, J. (2006). Modeling for meaningful learning. In D. Hung \& M. S. Khine (Eds), Engaged learning with emerging technologies (pp. 1-27). Dordrecht, The Netherlands: Springer.

Kamii, C., Lewis, B. A., \& Kirkland, L. (2001). Manipulatives: When are they useful? The Journal of Mathematical Behavior, 20(1), 21-31.

Kaput, J. J. (1989). Linking representations in the symbol systems of algebra. Research Issues in the Learning and Teaching of Algebra, 4, 167-194.

Kaput, J. J., Carraher, D. W., \& Blanton, M. L. (2008). Algebra in the early grades. Lawrence Erlbaum Associates/National Council of Teachers of Mathematics.

Kilpatrick, J., Swafford, J., \& Findell, B. (2001). Adding it up: Helping children learn mathematics. National Academies Press.

Koedinger, K. R., Alibali, M. W., \& Nathan, M. J. (2008). Trade-Offs between Grounded and Abstract Representations: Evidence from Algebra Problem Solving. Cognitive Science, 32(2), 366-397.

Knuth, E. J., Alibali, M. W., Hattikudur, S., McNeil, N. M., \& Stephens, A. C. (2008). The importance of equal sign understanding in the middle grades. Mathematics Teaching in the Middle School, 13(9), 514-519.

Kong, S. C. (2005). A cognitive tool for teaching the addition/subtraction of common fractions: A model of affordances. Computers \& Education, 45(2), 245-265.

Lappan, G., Fey, J. T., Fitzgerald, W. M., Friel, S. N., \& Phillips, E. D. (2006). Accentuate the Negative: Integers and Rational Numbers. Boston, MA: Pearson/Prentice Hall.

Lesh, R., Post, T., \& Behr, M. (1987). Representations and translations among representations in mathematics learning and problem solving. In C. Janvier, (Ed.), Problems of 
Representation in the Teaching and Learning of Mathematics, (pp. 33-40). Hillsdale, NJ: Lawrence Erlbaum.

Liebeck, P. (1990). Scores and foreits-An intuitive model for integer arithmetic. Educational Studies in Mathematics, 21(3), 221-239.

McNeil, N. M., \& Jarvin, L. (2007). When theories don’t add up: Disentangling the manipulatives debate. Theory Into Practice, 46(4), 309-316.

McNeil, N. M., Uttal, D. H., Jarvin, L., \& Sternberg, R. J. (2009). Should you show me the money? Concrete objects both hurt and help performance on mathematics problems. Learning and Instruction, 19(2), 171-184.

Mix, K. S., Levine, S. C., \& Huttenlocher, J. (1999). Early fraction calculation ability. Developmental Psychology, 35(1), 164.

Mousoulides, N. G., Christou, C., \& Sriraman, B. (2008). A modeling perspective on the teaching and learning of mathematical problem solving. Mathematical Thinking and Learning, 10(3), 293-304.

Moyer, P. S. (2001). Are we having fun yet? How teachers use manipulatives to teach mathematics. Educational Studies in Mathematics, 47(2), 175-197.

NAEP Question Tool. (2009). United States Department of Education. Retrieved from http://nces.ed.gov/nationsreportcard/itmrlsx/search.aspx?subject=mathematics

National Council of Teachers of Mathematics. (2000). Principles and Standards for School Mathematics. Reston, VA: Author.

National Governors Association Center for Best Practices \& Council of Chief State School Officers. (2010). Common Core State Standards for Mathematics. Washington, DC: Authors. 
Ni, Y. (2000). How Valid is it to Use Number Lines to Measure Children’s Conceptual Knowledge about Rational Number? Educational Psychology, 20(2), 139-152.

Olive, J. (1999). From fractions to rational numbers of arithmetic: A reorganization hypothesis. Mathematical Thinking and Learning, 1(4), 279-314.

Organisation for Economic Co-Operation and Development. (2010). PISA 2009 Assessment Framework. Paris: Organisation for Economic Co-operation and Development. Retrieved from http://www.oecd-ilibrary.org/content/book/9789264062658-en

Panasuk, R. M., \& Beyranevand, M. L. (2010). Algebra students’ ability to recognize multiple representations and achievement. International Journal for Mathematics Teaching and Learning, 1-21.

Pape, S. J., \& Tchoshanov, M. A. (2001). The role of representation(s) in developing mathematical understanding. Theory into Practice, 40(2), 118-127.

Peled, I., \& Carraher, D. W. (2007). Signed numbers and algebraic thinking. In J. Kaput, D. Carraher, \& M. Blanton (Eds.), Algebra in the Early Grades, (pp. 303-327). Mahwah, NJ: Lawrence Erlbaum.

Petrella, G. (2001). Subtracting integers: An affective lesson. Mathematics Teaching in the Middle School, 7(3), 150-153.

Reeves, C. A., \& Webb, D. (2004). Balloons on the rise: A problem-solving introduction to integers. Mathematics Teaching in the Middle School, 9(9), 476-482.

Saenz-Ludlow, A. (1994). Michael’s fraction schemes. Journal for Research in Mathematics Education, 25(1), 50-85. 
Saxe, G. B., Taylor, E. V., McIntosh, C., \& Gearhart, M. (2005). Representing fractions with standard notation: A developmental analysis. Journal for Research in Mathematics Education, 36(2), 137-157.

Scher, D., \& Goldenberg, E. P. (2001). A multirepresentational journey through the law of cosines. In A. Cuoco \& F. Curcio (Eds), The Roles of Representation in School Mathematics, (pp. 117-128). Reston, VA: National Council of Teachers of Mathematics Yearbook.

Schnepp, M. J., \& Nemirovsky, R. (2001). Constructing a foundation for the fundamental theorem of calculus. In A. Cuoco \& F. Curcio (Eds), The Roles of Representation in School Mathematics, (pp. 90-102). Reston, VA: National Council of Teachers of Mathematics Yearbook.

Schoenfeld, A. H. (1986). On having and using geometric knowledge. In J. Hiebert (Ed.), Conceptual and Procedural Knowledge: The Case of Mathematics, (pp. 225-241). Hillsdale, NJ: Lawrence Erlbaum Associates.

Schwarz, C. V., \& White, B. Y. (2005). Metamodeling knowledge: Developing students’ understanding of scientific modeling. Cognition and Instruction, 23(2), 165-205.

Sfard, A. (1991). On the dual nature of mathematical conceptions: Reflections on processes and objects as different sides of the same coin. Educational Studies in Mathematics, 22(1), 136.

Sherman, J., \& Bisanz, J. (2009). Equivalence in Symbolic and Nonsymbolic Contexts: Benefits of Solving Problems with Manipulatives. Journal of Educational Psychology, 101(1), 88100. 
Shore, F. S. (2005). Operating with integers: A familiar model under new contexts. Ohio Journal of School Mathematics, 52, 7-11.

Stephan, M. L. (2009). What are you worth? Mathematics Teaching in the Middle School, 15(1), $16-23$.

Stephan, M. L., \& Akyuz, D. (2012). A proposed instructional theory for integer addition and subtraction. Journal for Research in Mathematics Education, 43(4), 428-464.

Streefland, L. (1993). The design of a mathematics course a theoretical reflection. Educational Studies in Mathematics, 25(1-2), 109-135.

Tzur, R. (1999). An integrated study of children's construction of improper fractions and the teacher's role in promoting that learning. Journal for Research in Mathematics Education, 30(4), 390-416.

Uttal, D. H., O’Doherty, K., Newland, R., Hand, L. L., \& DeLoache, J. (2009). Dual representation and the linking of concrete and symbolic representations. Child Development Perspectives, 3(3), 156-159.

Van den Heuvel-Panhuizen, M. (2003). The didactical use of models in realistic mathematics education: An example from a longitudinal trajectory on percentage. Educational Studies in Mathematics, 54(1), 9-35.

VanLehn, K. (2013). Model construction as a learning activity: a design space and review. Interactive Learning Environments, 21(4), 371-413.

Vlassis, J. (2002). The balance model: Hindrance or support for the solving of linear equations with one unknown. Educational Studies in Mathematics, 49(3), 341-359. 
Whitacre, I., Bishop, J. P., Lamb, L. L., Philipp, R. A., Schappelle, B. P., \& Lewis, M. L. (2012). Happy and sad thoughts: An exploration of children’s integer reasoning. The Journal of Mathematical Behavior, 31(3), 356-365.

White, T., \& Pea, R. (2011). Distributed by design: On the promises and pitfalls of collaborative learning with multiple representations. Journal of the Learning Sciences, 20(3), 489-547.

Zbiek, R. M., \& Conner, A. (2006). Beyond motivation: Exploring mathematical modeling as a context for deepening students’ understandings of curricular mathematics. Educational Studies in Mathematics, 63(1), 89-112. 
Table 1. Types of integer addition and subtraction problems

\begin{tabular}{|c|c|c|}
\hline \multicolumn{2}{|r|}{ Problem Type } & \multirow{2}{*}{$\begin{array}{c}\text { Example problem } \\
5+3\end{array}$} \\
\hline Addition, $\mathrm{a}+\mathrm{b}$ & A-1. $a$ and $b$ both positive, $|a| \geq|b|$ & \\
\hline & A-2. $a$ and $b$ both negative, $|a| \geq|b|$ & $5+-3$ \\
\hline & A-3. $\mathrm{a}$ and $\mathrm{b}$ both positive, $|\mathrm{a}|<|\mathrm{b}|$ & $3+5$ \\
\hline & A-4. $a$ and $b$ both negative, $|\mathrm{a}|<|\mathrm{b}|$ & $3+-5$ \\
\hline & A-5. $a$ and $b$ different signs, $a>0$ & $5+{ }^{-} 3$ \\
\hline & A-6. $a$ and b different signs, $b>0$ & $5+3$ \\
\hline \multirow[t]{6}{*}{ Subtraction, a - b } & S-1. $a$ and $b$ both positive, $|a| \geq|b|$ & $5-3$ \\
\hline & S-2. $a$ and $b$ both negative, $|a| \geq|b|$ & $5-{ }^{-} 3$ \\
\hline & S-3. $\mathrm{a}$ and $\mathrm{b}$ both positive, $|\mathrm{a}|<|\mathrm{b}|$ & $3-5$ \\
\hline & S-4. $\mathrm{a}$ and $\mathrm{b}$ both negative, $|\mathrm{a}|<|\mathrm{b}|$ & $3-{ }^{-} 5$ \\
\hline & S-5. $a$ and $b$ different signs, $a>0$ & $5-{ }^{-} 3$ \\
\hline & S-6. $a$ and $b$ different signs, $b>0$ & $5-3$ \\
\hline
\end{tabular}


Figure 1. Using renaming to model 3 - 5

Start with 3 black chips


Figure 2. Two possible (but incorrect) ways to use an area model for $\frac{1}{4}+\frac{1}{6}$
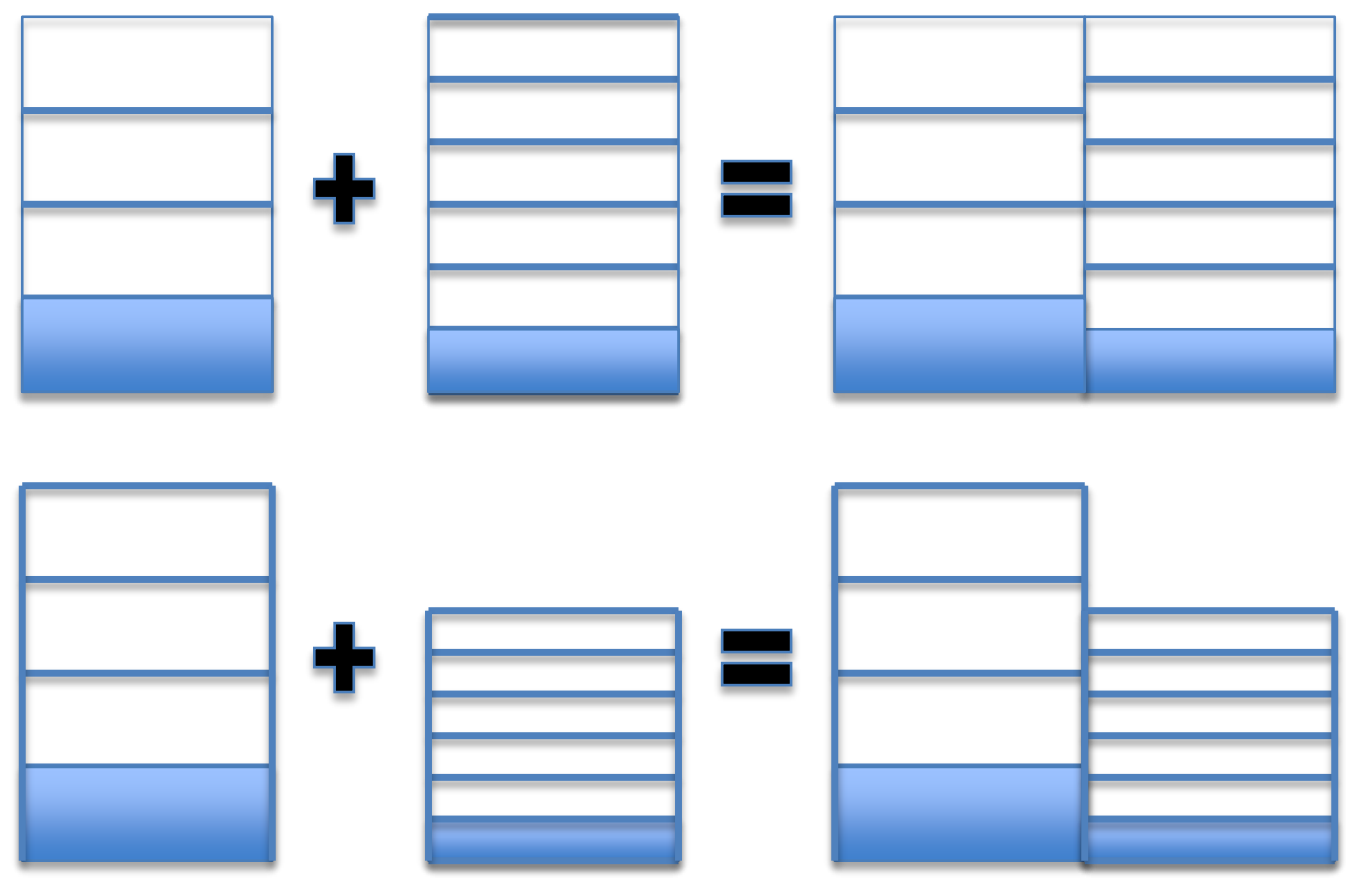
Figure 3. A correct area model construction of $\frac{1}{4}+\frac{1}{2}=\frac{1}{4}+\frac{2}{4}$

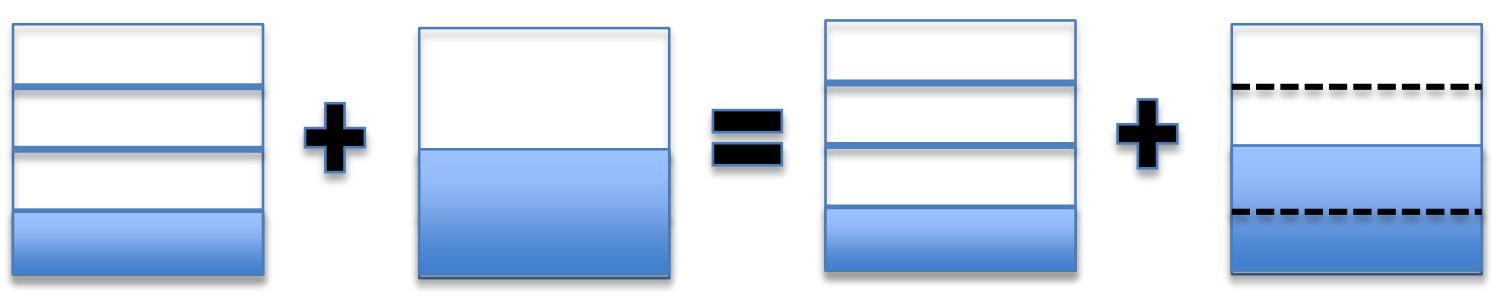


Figure 4. A correct area model construction of $\frac{1}{4}+\frac{1}{6}=\frac{3}{12}+\frac{2}{12}=\frac{5}{12}$

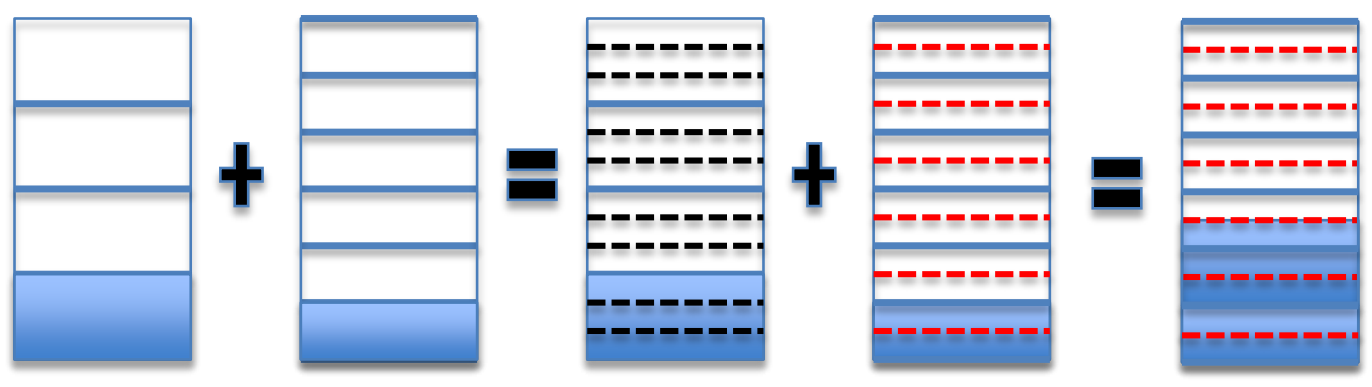


Figure 5. A correct area model construction of $\frac{1}{4}+\frac{3}{2}=\frac{1}{4}+\frac{6}{4}=\frac{7}{4}$
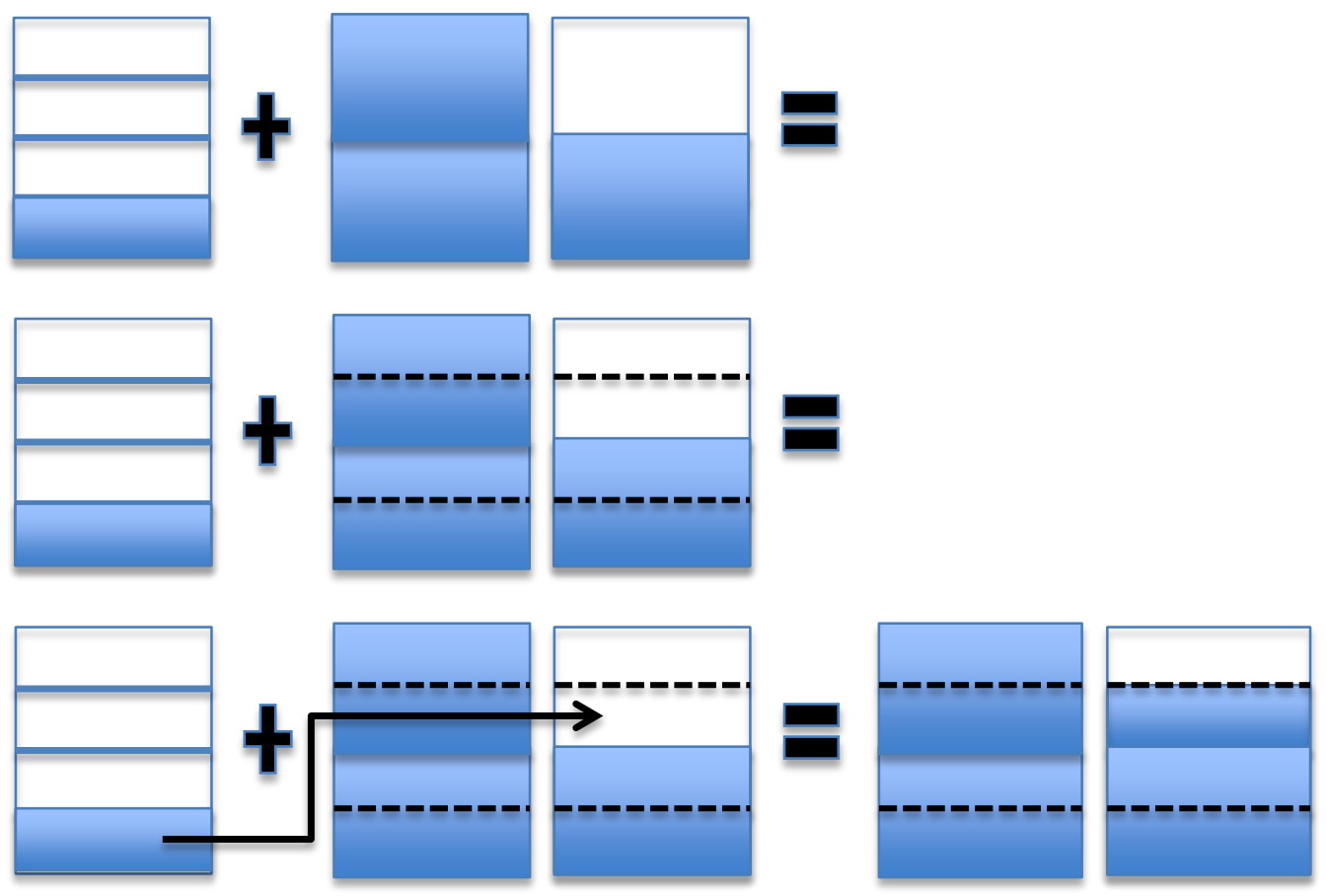